\title{
THE STUDY OF HUMORAL FACTORS OF ADAPTIVE IMMUNITY IN PATIENTS WITH NON-HODGKIN'S LYMPHOMAS
}

\author{
Tillyashaykhov M. N., Abdiganiyeva S. R., Abdurakhmonov D. A., Tuidzhanova H. Kh., \\ Isroilova F. Kh., Alimova S. S. \\ Republican specialized scientific-practical medical center of oncology and radiology of Ministry of \\ health of the Republic of Uzbekistan
}

DOI: https://doi.org/10.31435/rsglobal_sr/31072019/6610

\section{ARTICLE INFO}

Received 17 May 2019

Accepted 11 July 2019

Published 31 July 2019

\section{KEYWORDS}

adaptive cellular immunity, humoral immunity, polychemotherapy, lymphomas, non-Hodgkin lymphoma, immunoglobulins.

\begin{abstract}
It is known that humoral factors of immunity play an important function of mediators in the cascade development of the immune response and can determine the effectiveness of the final, effector reactions of cellular immunity in the inactivation and elimination of antigens. Serum concentrations of major immunoglobulins IgG, IgA, IgM in NHL were analyzed. The highest serum content of IgG and IgA was revealed in the groups of patients with virus carrier. It has been established that one of the most important humoral markers of immunity is the circulating immune complexes (CIC). It has been established that one of the most important biological functions of immunoglobulins is antigen binding and the formation of CIC. A high level of CIC in NHL may be due not only to the activation of the immune response, but also to the suppression of the mechanisms of their elimination. Therefore, based on the results obtained, with NHL there is a pronounced imbalance of humoral immunity. CIC of large and small sizes are also increased, however, the highest increase in CIC was observed in groups of patients before chemotherapy with virus-bearing. An increase in the main immunoglobulins indicates the presence of humoral imbalance, and an increase in the CIC indicates the presence of intoxication of the body either due to the decay of the tumor cells themselves and infected cells, which almost always indicates the progression of the pathological process.
\end{abstract}

Citation: Tillyashaykhov M. N., Abdiganiyeva S. R., Abdurakhmonov D. A., Tuidzhanova H. Kh., Isroilova F. Kh., Alimova S. S. (2019) The Study of Humoral Factors of Adaptive Immunity in Patients with Non-Hodgkin's Lymphomas. Science Review. 6(23). doi: 10.31435/rsglobal_sr/31072019/6610

Copyright: $\quad$ (C) $2019 \quad$ Tillyashaykhov M. N., $\quad$ Abdiganiyeva S. R., $\quad$ Abdurakhmonov D. A., Tuidzhanova H. Kh., Isroilova F. Kh., Alimova S. S. This is an open-access article distributed under the terms of the Creative Commons Attribution License (CC BY). The use, distribution or reproduction in other forums is permitted, provided the original author(s) or licensor are credited and that the original publication in this journal is cited, in accordance with accepted academic practice. No use, distribution or reproduction is permitted which does not comply with these terms.

Despite a significant deepening in the last decade of ideas in the etiology, immunopathogenesis, course and progression of malignant processes, many questions regarding the mechanisms of the development of the pathological process and its course, evaluation of treatment effectiveness, remain open $[10,12]$. Moreover, in recent years, many etiopathogenetic factors, such as viruses, which have a pronounced carcinogenic factor, have been understood. So, an important role in the course and effectiveness of therapy for lymphomas belongs to the cellular and humoral factors of the immune system [4,7].

At present, great attention is paid to the study of immunological mechanisms in the development and progression of lymphomas. An important issue remains the immunodiagnostics of cellular and humoral immunity. As the literature shows, publications devoted to the study of immunity are sporadic. Basically, articles are devoted to clinical study and the description of the results of treatment methods, while there are no works of a pathogenetic nature. Reliable data can only be 
obtained by analyzing a sufficiently large amount of clinical material that makes it possible to study the frequency of occurrence of various NHL variants; comparison of clinical, morphological and immunological data, as well as the results of treatment of T- and B-cell lymphomas, which opens up the possibility of improving the diagnosis and individualization of chemotherapy programs depending on the immunophenotypic characteristics of tumor cells $[1,3,8,12]$.

Based on the foregoing, we evaluated the humoral factors of the immune system in patients with NHL depending on the virus carrier.

Purpose of the study. To study the main humoral parameters of immunity in patients with nonHodgkin's lymphomas in order to understand the etiopathogenetic features of the course of the disease.

Materials and research methods. In our study, patients with non-Hodgkin's lymphomas (NHL) were divided into 2 groups: group I - patients with established virus carriers; group II - patients in the control group with no virus carrier. In the distribution of NHL patients by age, it was found that virus carriage leads to a rejuvenation of the disease: the peak incidence rate in group I is up to 30 years, while the same indicator for group II is over 50 years. In sick men with virus carriers, the average age was $35.6 \pm$ 4.56 years, among women $-27.2 \pm 5.24$ years, in the control group, the average age of men was $60.7 \pm 3.80$ years, women $-45.5 \pm 6.97$ years. The proportion of women in group I was $21.7 \pm 6.44 \%$, men $-78.3 \pm$ $6.44 \%$; in group II, women accounted for $44.4 \pm 7.75 \%$, men $-55.6 \pm 7.75 \%$.

In all patients, the diagnosis was established on the basis of data and the results of a comprehensive study (clinical, biochemical, radiological, ultrasound, CT, myelogram, morphological).

The lesion zones for non-Hodgkin lymphomas in patients with viral infection (group I) most often occurred in the neck and axillary lymph nodes (more than 50\%), then in the mediastinal, supraclavicular, retroperitoneal and inguinal (25-45\%), the least significant was the defeat of the iliac 1 / nodes, spleen, Valdeyer (20\% or less).

In control group II, the picture of lymph node lesions differed from the experimental group patients with affected cervical 1 / nodes were more than $70 \%$, while the remaining lesion zones were less common: axillary, supraclavicular, inguinal $1 /$ nodes malignantly transformed in 30-40\% of cases; mediastinal, retroperitoneal, iliac - in less than $20 \%$ of cases; Valdeyer ring damage was observed in more than $60 \%$ of patients. Viral infection changes the picture of lymph node damage in patients with NHL in comparison with patients without viral load: in group I, axillary, mediastinal, supraclavicular, retroperitoneal, and inguinal 1 / nodes were transformed malignantly (25-45\%). Group I patients were most often infected with HSV herpes simplex virus and Epstein-Barr virus (65-80\%). Cytomegalovirus infection (CMV), human papilloma virus (HPV) in $43.4 \pm 7.7 \%$ of patients, and Varicella-Zoster virus were found in $26.0 \pm 6.8 \%$ and $8.6 \pm 4.4 \%$, respectively. The examination included patients undergoing examination in the chemotherapy department. All patients underwent clinical and laboratory blood tests, which included the study of a general analysis of blood and urine, biochemical and immunological parameters, as well as the blood coagulation system. Patients underwent a comprehensive clinical and instrumental examination aimed at clarifying the prevalence of the tumor process and identifying existing complications.

Immunological studies included the study of the humoral parameters of the immune system of patients. The humoral immunity parameters were determined by studying the main immunoglobulins A, M, G using commercial test systems for enzyme-linked immunosorbent assay produced by "Human", Germany.

When conducting a statistical analysis of the data presented in the work, the results of the study were entered into databases prepared in the Microsoft Excel XP program. Numerical (continuous) values were presented as arithmetic means and mean errors $(\mathrm{M} \pm \mathrm{m})$. Comparison of quantitative characteristics was carried out using Student's criterion, for continuous variables - paired Student's criterion. $\mathrm{P}<0.05$ was taken as a boundary comparative criterion of statistical significance.

\section{The obtained research results and their discussion.}

It has been established that the functional usefulness of B-lymphocytes in the immune response is characterized by the production of immunoglobulins [10,12]. It is known that immunoglobulins play an important function of mediators in the cascade development of the immune response and can partly determine the effectiveness of the final, effector responses of cellular immunity in the inactivation and elimination of antigens [7,8]. It is also known that circulating antibodies are one of the effector factors of immunity, which provides antigen-specific protection $[1,3,4,8]$. We have analyzed the serum concentrations of the main immunoglobulins $\operatorname{IgG}, \operatorname{IgA}, \operatorname{IgM}$ in NHL. As can be seen from the data presented, the content of the main serum immunoglobulins varied widely. The highest serum IgG content was detected in the group of patients before treatment without virus carrier, and the lowest content was noted in the group of patients with virus carrier, that is, due to 
a factor that suppresses immunity. The serum IgM content in almost all groups of patients with NHL was within the normative values, and there were no specific deviations between the groups of patients. Thus, the serum IgG content in the group of patients before treatment with virus-bearing was $1374.5 \pm$ $46.4 \mathrm{mg} \%$, in the group of patients without virus-bearing $-1287.9 \pm 56.8 \mathrm{mg} \%$, with a standard value of $1148.5 \pm 35.6 \mathrm{mg} \%$. Analysis of IgA content revealed the presence of a significant increase in serum IgA in all groups of patients with NHL. Moreover, the highest content was noted in the group of patients with virus carrier. Consequently, the humoral immunity was characterized by an increase in serum concentrations of IgG and IgA in groups of patients with NHL.

One of the most important humoral markers of immunity is the circulating immune complexes (CICs). It has been established that one of the most important biological functions of immunoglobulins is antigen binding and the formation of CICs [6,12]. An important characteristic of the CIC is their size, which can be large and small. The analysis showed that the CIC of large and small sizes in all groups of patients were significantly increased. So, the CIC of large quantities were significantly increased before treatment. As for the CIC of small quantities, a significant increased content is also observed. The highest average value of small CIC was revealed in groups of patients before treatment and after treatment without immunotherapy. Apparently, this is due to the lack of necessary detoxification and effects on the functioning of the immune system. Also, a CIC of $4 \%$ of small values are observed, the smallest value close to normal in the group of patients without virus carrier. It is known that CIC 3\% of large quantities formed with an excess of antibodies, although they are able to bind complement, are large, insoluble, quickly phagocytized and have low pathogenicity $[2,3,5]$. The greatest pathological potential is possessed by soluble immune complexes of small sizes, which were formed with an excess of antigen [4,7]. A high level of CIC can be caused not only by activation of the immune response, but also by suppression of the mechanisms of their elimination $[2,6,10,11]$. The latter, apparently, is associated with a weakening of the function of the cells of the monocyte-macrophage system - cells that absorb and disintegrate the immune complexes. Therefore, activation of the humoral immunity is observed along with severe depression of the cellular immunity.

Thus, based on the results obtained, it is seen that with NHL there is a pronounced imbalance of humoral immunity. CIC of large and small sizes are also increased, however, the largest increase in CIC was observed in groups of patients prior to chemotherapy with virus-bearing compared with data from patients without virus-bearing. An increase in major immunoglobulins indicates the presence of humoral imbalance, and an increase in CIC indicates intoxication of the body either due to the decay of the tumor cells themselves and infected cells. An increase in CIC of $4 \%$ always indicates the progression of the pathological process and is a marker of the progression or worsening of the clinical course. CIC3\% quickly disintegrate in the body, so they have no pathological potential.

\section{REFERENCES}

1. Antoni, P.A. CD4+CD25+ T regulatory cells, immunotherapy of cancer, and interleukin-2 // J. Immunother.- 2005. -Vol.28.-P.120-128.

2. Antony, G.K. Interleukin 2 in cancer therapy // Curr Med. Chem. 2010.-Vol.17 (29).-P.3297-3302.

3. Lindeman N. et al. One patient, two lymphomas. Simultaneous primary gastric marginal zone lymphoma and primary duodenal follicular lymphoma // Arch. Pathol. Lab. Med. -2004. Vol. 128, N9.-P. 1035-1038.

4. Malani A.K., Gupta C., Weigand R.T. et al. Spinal Burkitt's lymphoma in adults // Clin. Lymphoma Myeloma. 2006. - Vol. 6, N 4. - P. 333-336.

5. Manzur A., Zaidi S. Hypopigmented mycosis fungoides in a 10-year-old boy // Dermatol. Online J. 2006. Vol. 31, N 6. - P. 21.

6. Marte A., Sabatino M., Cautiero P. et al. Unexpected finding of laparoscopic appendectomy: appendix MALT lymphoma in children // Pediatr. Surg. Int. 2007. - Vol. 7. -P. 119-123.

7. Mawanda O.W. Aspects of epidemiological and clinical features of patients with central nervous system Burkitt's lymphoma in Kenia // East. Afr. Med. J. 2004. - Vol. 8. - P. 97103.

8. Mawanda O.W. Clinical characteristics of Burkitt's lymphoma seen in Kenyan patients // East. Afr. Med. J. 2004. - N 8. - P. 78-89.

9. Sharkey R., Karacay H., Johnson C. et al. Pretargeted versus directly targeted radioimmu-notherapy combined with anti-CD20 antybody consolidation therapy of Non-Hodgkin lymphoma // J.Nucl.Med. 2009. - Vol. 17.-P. 123-128.

10. Wilson W.H., Grossbard M.L., Pittaluga S. et al. Dose-adjusted EPOCH chemotherapy for untreated large B-cell lymphomas: A pharmacodynamic approach with high efficacy// Blood. 2002. - Vol. 99. - P. 2685-2693.

11. Windsor R., Stiller C., Webb D. Peripheral T-cell lymphoma in childhood: population-based experience in the United Kingdom over 20 years // Pediatr. Blood Cancer. - 2007. -Vol. 11.-P. 87-91.

12. Wrobel G., Kazanowska B., Chybicka A. et al. Progress in the treatment of non-Hodgkin's lymphoma (NHL) in children. The report of Polish Pediatric Leukaemia/lymphoma Study Group (PPLLSG) // Przegl. Lek. 2004. - Vol. 61, N 2. - P. 45-48. 